\title{
Cerebral Hypoperfusion in Progressive Supranuclear Palsy (PSP) and Corticobasal Syndrome (CBS)
}

Piotr Alster ( $\nabla$ piotr.alster@gmail.com )

Warszawski Uniwersytet Medyczny https://orcid.org/0000-0002-5371-6817

Michał Nieciecki

Mazowiecki Szpital Brodnowski w Warszawie Sp zoo

Dariusz Koziorowski

Warszawski Uniwersytet Medyczny

Ingeborga Charzyńska

Mazowiecki Szpital Brodnowski w Warszawie Sp zoo

\section{Leszek Królicki}

Warszawski Uniwersytet Medyczny

Andrzej Friedman

Warszawski Uniwersytet Medyczny

Research article

Keywords: PSP, CBS, rCBF, SPECT, hypoperfusion

Posted Date: April 30th, 2020

DOI: https://doi.org/10.21203/rs.2.9229/v2

License: (9) (i) This work is licensed under a Creative Commons Attribution 4.0 International License.

Read Full License 
The authors have withdrawn this preprint from Research Square 